Dear Author,

Please, note that changes made to the HTML content will be added to the article before publication, but are not reflected in this PDF.

Note also that this file should not be used for submitting corrections. 


\title{
Targeting cyst wall is an effective strategy in improving the efficacy of marketed contact lens disinfecting solutions against Acanthamoeba castellanii cysts
}

\author{
Farhat Abjani ${ }^{\mathrm{a}, 1}$, Naveed Ahmed Khan ${ }^{\mathrm{b}, 1, *}$, Farzana Abubakar Yousuf ${ }^{\mathrm{a}}$, \\ Ruqaiyyah Siddiqui ${ }^{\text {b }}$ \\ a Department of Biological and Biomedical Sciences, Aga Khan University, Pakistan \\ ${ }^{\mathrm{b}}$ Department of Biological Sciences, Faculty of Science and Technology, Sunway University, Malaysia
}

\section{A R T I C L E I N F O}

Article history:

Received 7 September 2015

Received in revised form 29 October 2015

Accepted 24 November 2015

\section{Keywords:}

Keratitis

Contact lens

Disinfecting solution

Cellulase

\begin{abstract}
A B S T R A C T
Acanthamoeba cysts are highly resistant to contact lens disinfecting solutions. Acanthamoeba cyst wall is partially made of 1,4 $\beta$-glucan (i.e., cellulose) and other complex polysaccharides making it a hardy shell that protects the resident amoeba. Here, we hypothesize that targeting the cyst wall structure in addition to antiamoebic compound would improve the efficacy of marketed contact lens disinfecting solutions. Using chlorhexidine as an antiamoebic compound and cellulase enzyme to disrupt cyst wall structure, the findings revealed that combination of both agents abolished viability of Acanthamoeba castellanii cysts and trophozoites. When tested alone, none of the agents nor contact lens disinfecting solutions completely destroyed $A$. castellanii cysts and trophozoites. The absence of cyst wall-degrading enzymes in marketed contact lens disinfecting solutions render them ineffective against Acanthamoeba cysts. It is concluded that the addition of cyst wall degrading molecules in contact lens disinfecting solutions will enhance their efficacy in decreasing the incidence of Acanthamoeba effectively.
\end{abstract}

(C) 2015 Published by Elsevier Ltd on behalf of British Contact Lens Association.

\section{Introduction}

Acanthamoeba keratitis is a serious human infection that can lead to blindness and often associated with inappropriate use of the contact lenses [1-3]. First reported in early 1970s [4], Acanthamoeba keratitis has remained a significant problem, despite our advances in antimicrobial chemotherapy and supportive care [5,6]. Acanthamoeba keratitis is characterized by blurred vision, sensitivity to light, conjunctivitis, eye lid swelling, and reddened eye with watery discharge, and severe pain [7]. Approximately $85-88 \%$ cases of Acanthamoeba keratitis are associated with the use of contact lens and hence contact lens wearers are at increased risk of this infection $[8,9]$. Acanthamoeba keratitis is often linked to contact lens disinfectants that fail to effectively decontaminate contact lens. A recent outbreak in the USA that reported to affect 138 people led to recall of contact lens disinfectants by the FDA and Health, Canada and has resulted in over 150 lawsuits against the manufacturer [10-12]. The available contact lens disinfecting solutions are often found ineffective or toxic to human cells, if not rinsed properly [13]. Recently, Lakhundi et al. [14] tested nine different contact lens disinfectants containing chlorhexidine or polyhexamethyl biguanide against Acanthamoeba castellanii and found none to be effective in destroying amoebae, albeit bacterial pathogens were killed. This is possibly due to low concentration of chlorhexidine or polyhexamethyl biguanide in contact lens disinfectants. A major challenge in eradicating Acanthamoeba is its ability to transform from an active trophozoite stage to a resistant cyst stage that remains dormant with little metabolic activity [15-17]. This may explain ineffectiveness of contact lens disinfectants containing chlorhexidine or polyhexamethyl biguanide against $A$. castellanii [14]. Recent work has shown that Acanthamoeba cyst wall is partially made of 1,4 $\beta$-glucan (i.e., cellulose) and other complex polysaccharides [16-18] making it a hardy shell that protects the resident amoeba. Here, we hypothesize that targeting the cyst wall structure together with antiamoebic compound, chlorhexidine, is an effective chemotherapeutic strategy to diminish viable amoeba. Using chlorhexidine as an antiamoebic compound and cellulase enzyme to disrupt cyst wall structure, we determined whether combination of both agents can enhance efficacy of marketed 
Table 1

List of contact lens disinfectants used in the present study, their ingredients, type of solution, minimum recommended disinfection time (MDRT) and manufacturer.

\begin{tabular}{|c|c|c|c|c|}
\hline Solution & Ingredients & Type & $\begin{array}{l}\text { Minimum } \\
\text { recommended } \\
\text { disinfection time }\end{array}$ & Manufacturer \\
\hline $\begin{array}{l}\text { Ultimate } \\
\text { plus }\end{array}$ & $\begin{array}{l}\text { Polyhexamethylene biguanide, tromethamine, tyloxapol, hydroxy propyl } \\
\text { methylcellulose (HPMC) and edetate disodium }\end{array}$ & $\begin{array}{l}\text { Multipurpose } \\
\text { solution }\end{array}$ & $4 \mathrm{~h}$ & $\begin{array}{l}\text { ELKO Organization } \\
\text { (Pvt.), Ltd. }\end{array}$ \\
\hline Dura Plus & $\begin{array}{l}\text { Edetate disodium, poloxamine, sodium chloride and aquahydrate }{ }^{\mathrm{TM}} \text {; preserved with } \\
\text { OPTIMED (Polyaminopropyl Biguanide). Contains no chlorhexidine, no thimerosal and no } \\
\text { sorbic acid }\end{array}$ & $\begin{array}{l}\text { Multipurpose } \\
\text { solution }\end{array}$ & $4 \mathrm{~h}$ & $\begin{array}{l}\text { Sipic International } \\
\text { Texas, USA }\end{array}$ \\
\hline $\begin{array}{l}\text { Opti-Free } \\
\text { Express }\end{array}$ & $\begin{array}{l}\text { Sodium chloride, sorbitol, edetate disodium, boric acid, aminomethyl propanol, citrate } \\
\text { and tetronic }{ }^{\mathbb{R}} \text { (polidronium chloride) } 0.001 \% \text { and ALDOX }{ }^{\mathbb{R}} \text { (myristamidopropyl } \\
\text { dimethylamine) } 0.0005 \%\end{array}$ & $\begin{array}{l}\text { Multi-purpose } \\
\text { disinfecting } \\
\text { solution }\end{array}$ & $6 \mathrm{~h}$ & $\begin{array}{l}\text { Alcon Laboratories, } \\
\text { Inc., Fort Worth, TX }\end{array}$ \\
\hline
\end{tabular}

contact lens disinfectants, including Opti-Free Express (Alcon Laboratories, Inc.), Ultimate Plus (ELKO Organization (Pvt.) Ltd.), Dura Plus (SIPIC International) against $A$. castellanii trophozoites 2 and cysts, in vitro.

\section{Methods}

All chemicals were purchased from Sigma Laboratories (St. Louis, USA) or Oxoid (Hampshire, England) unless otherwise stated. Three Ultimate plus, Dura Plus, Opti-Free Express were purchased from local pharmacy in Karachi, Pakistan. A. castellanii belonging to the T4 genotype, isolated from a keratitis patient, was purchased from the American Type Culture Collection (ATCC 50492). A. castellanii was routinely cultured in PYG medium [proteose peptone $0.75 \%(\mathrm{w} / \mathrm{v})$, yeast extract $0.75 \%(\mathrm{w} / \mathrm{v})$, and glucose $1.5 \%(\mathrm{w} / \mathrm{v})]$ in $\mathrm{T}-75$ tissue culture flasks at $37^{\circ} \mathrm{C}$ without shaking [19]. The media were refreshed $15-20 \mathrm{~h}$ prior to experiments. A. castellanii adhering to flasks represented the trophozoite form and were collected by placing the flasks on ice for $30 \mathrm{~min}$ with gentle agitation and used as trophozoites.

To obtain cysts, amoebae trophozoites were inoculated on non-nutrient agar plates (without bacteria) at $30^{\circ} \mathrm{C}$ and plates incubated for 14 days. Following this incubation, cysts were scraped off from the agar surface using $10 \mathrm{~mL}$ of sterile distilled water using a cell scraper. Next, cysts were centrifuged at $2000 \times \mathrm{g}$ for $10 \mathrm{~min}$. The supernatant was aspirated and pellet resuspended in phosphate buffered saline and cysts enumerated using a haemocytometer.

Assays were performed on A. castellanii to evaluate amoebicidal effects of contact lens disinfectants in the presence and absence of antiamoebic drug and/or cellulase. The contact lens disinfection solutions used in this study along with their active ingredients and manufacturers' instructions are listed in Table 1 . Briefly, $5 \times 10^{5} \mathrm{~A}$. castellanii trophozoites or $5 \times 10^{4} A$. castellanii cysts were incubated in contact lens disinfectants, together with various concentrations of chlorhexidine and/or various units of cellulase (final volume: $200 \mu \mathrm{L}$ in Eppendorf tubes). The tubes were incubated at room temperature for recommended time, as per manufacturers' instructions. Following this incubation, the number of viable amoebae was determined by adding $0.1 \%$ Trypan blue exclusion staining (cells stained blue were considered nonviable while live cells were unstained). The numbers of amoebae were enumerated by haemocytometer counting. Additionally, viability of amoebae was determined using survival

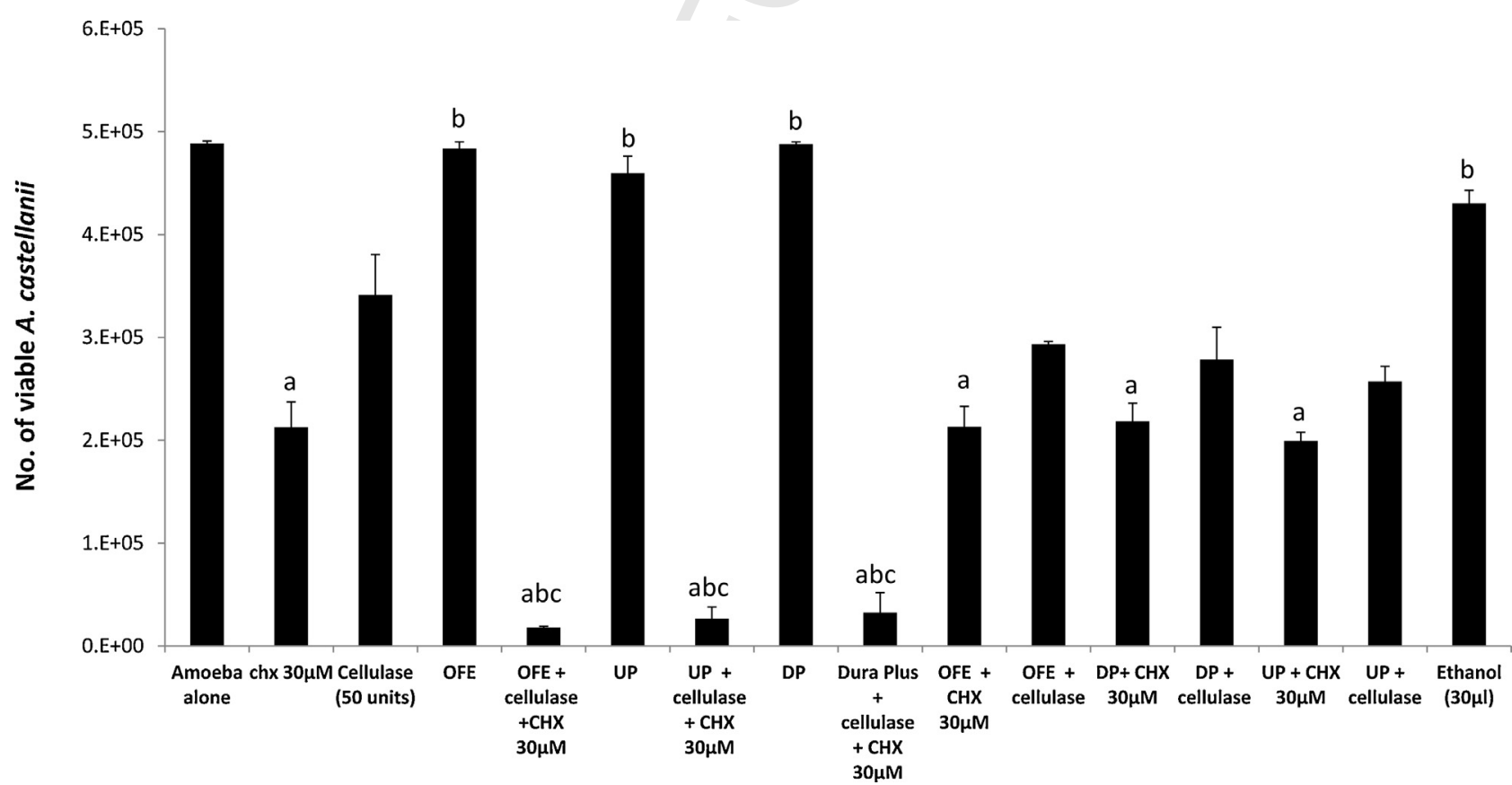

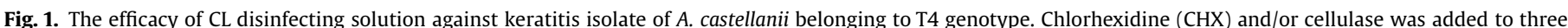

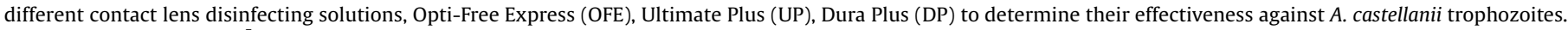

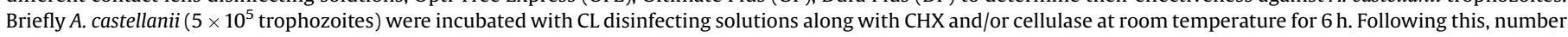

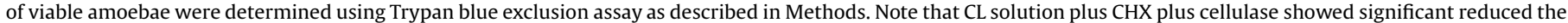

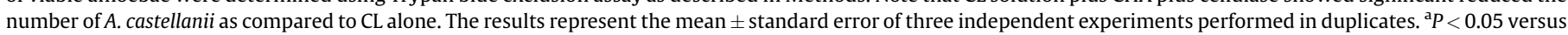
Acanthamoeba alone, ${ }^{b} P<0.05$ versus chlorhexidine alone, and ${ }^{c} P<0.05$ versus cellulase alone. 


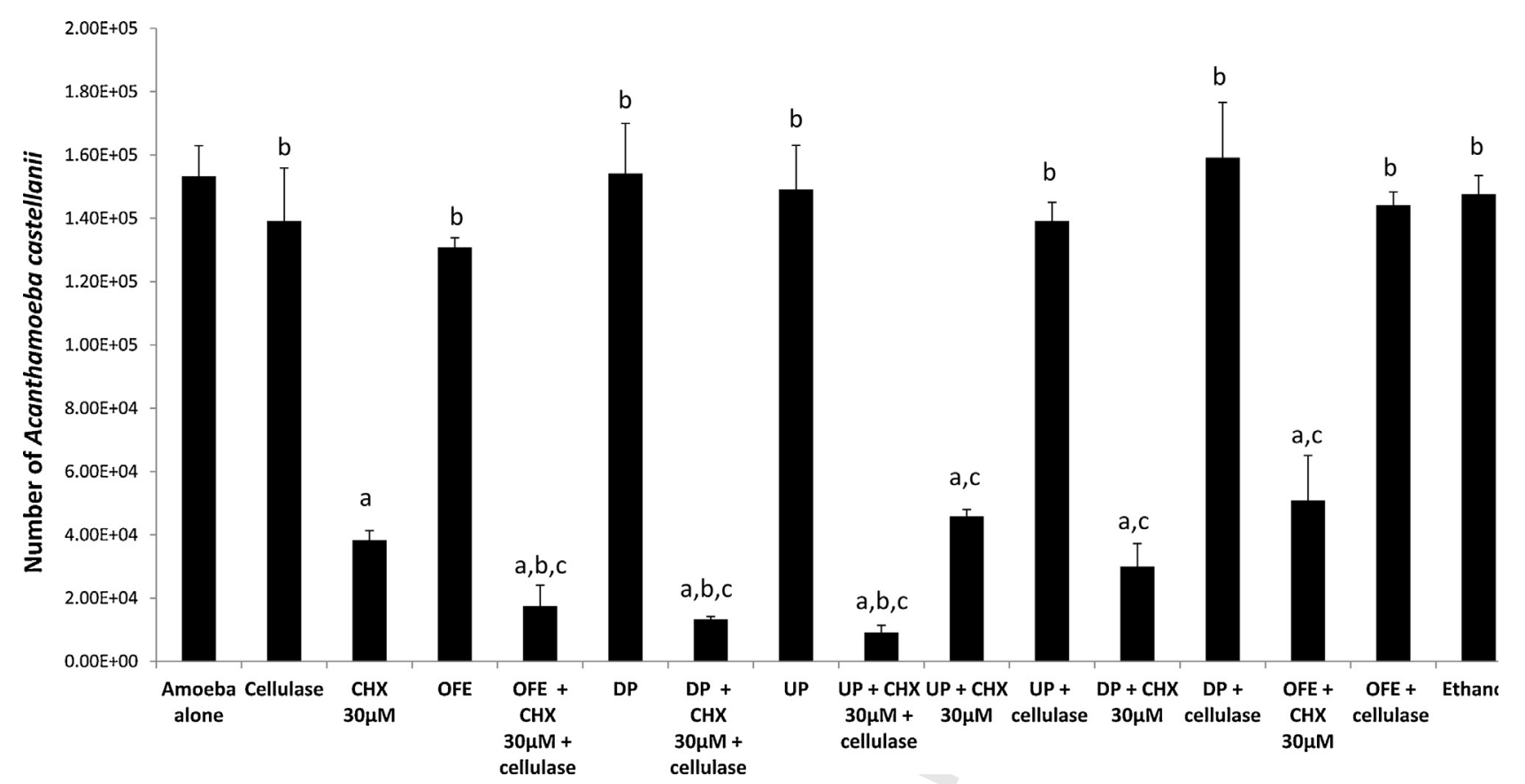

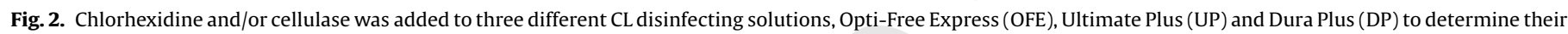

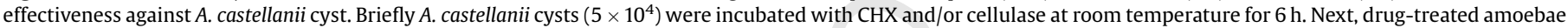

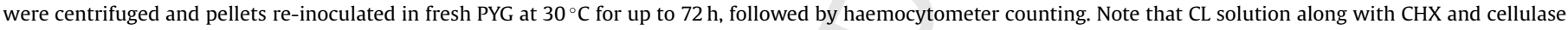

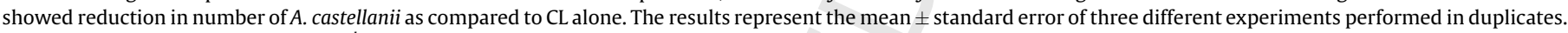
${ }^{\mathrm{a}} P<0.05$ versus Acanthamoeba alone, ${ }^{\mathrm{b}} \mathrm{P}<0.05$ versus chlorhexidine alone, and ${ }^{\mathrm{c}} \mathrm{P}<0.05$ versus cellulase alone.

assays. Briefly, amoebae post-treatment, were resuspended in $1 \mathrm{~mL}$ of PBS and centrifuged at $1500 \times g$ for $10 \mathrm{~min}$. The supernatant was discarded and pellet resuspended in PBS. This process was repeated $3 \times$ to remove residual drugs, contact lens disinfectant, and cellulase. Finally, amoebae pellet was resuspended in $500 \mu \mathrm{L}$ of growth medium, i.e., PYG and inoculated in 24-well plates for $72 \mathrm{~h}$ at $30^{\circ} \mathrm{C}$. A. castellanii in Roswell Park Memorial Institute- 1640 (RPMI) medium alone served as negative control, while amoebae incubated with chlorhexidine alone served as positive control. All experiments were performed at least 3 times, in duplicate. The data are presented as mean \pm standard error. For statistical comparisons, differences between groups were analyzed by a one-way analysis of variance (ANOVA), followed by Dennett's post-hoc test. A value of $P<0.05$ was considered to be statistically significant.

\section{Results}

A. castellanii incubated with RPMI alone yielded $4.9 \times 10^{5}$ amoebae on average. The solvent alone had no effect on the viability of A. castellanii (Fig. 1). All three contact lens disinfectants, Ultimate plus, Dura Plus, and Opti-Free Express were ineffective in killing A. castellanii trophozoites as shown in Fig. 1. When contact lens disinfectants-treated amoebae were re-inoculated in fresh growth medium, PYG, healthy trophozoites emerged within $24 \mathrm{~h}$. Contact lens disinfectants plus chlorhexidine (up to $30 \mu \mathrm{M}$ ) exhibited significant amoebicidal effects on the viability of $A$. castellanii trophozoites $(P<0.05)$, but when chlorhexidine-treated amoebae were re-inoculated in PYG, healthy trophozoites emerged at $72 \mathrm{~h}$, albeit, in reduced numbers. In contrast, contact lens disinfectants in the presence of cellulase (50 units) and chlorhexidine $(30 \mu \mathrm{M})$ abolished viability of $A$. castellanii trophozoites (Fig. 1). When incubated with growth medium, post-treatment, no viable amoebae were observed for up to $72 \mathrm{~h}$.

Cysticidal assays were performed to determine the effectiveness of contact lens disinfecting solutions in the presence of chlorhexidine and cellulase. A. castellanii cysts incubated with the solvent alone remained viable (Fig. 2) and excysted as viable trophozoites upon inoculation in PYG (Fig. 3). Similarly, contact lens disinfectants had no cysticidal" effects as demonstrated by Trypan blue staining and survival assay using PYG. Cellulase alone as well as in combination with contact lens disinfecting solution did not affect viability of cyst (Figs. 2 and 3 ). When chlorhexidine $(30 \mu \mathrm{M})$ was included with contact lens disinfecting solution, it showed significant cysticidal effects $(P<0.05)$ (Fig. 2$)$, however viable amoebae were observed upon inoculation in PYG. When both chlorhexidine $(30 \mu \mathrm{M})$ and cellulase $(30 \mu \mathrm{M})$ were added to contact lens disinfectants, the viability of $A$. castellanii cysts was abolished, as determined by Trypan blue exclusion assay and amoebae did not emerge as viable trophozoites in PYG (Figs. 2 and 3). These findings were consistent with all contact lens disinfectants tested in the present study. Similar results were observed when both chlorhexidine $(30 \mu \mathrm{M})$ and cellulase $(30 \mu \mathrm{M})$ were added to PBS, in the absence of contact lens disinfectants (data not shown). These findings are consistent with our previous findings [14], which showed that marketed contact lens disinfectants tested are ineffective against $A$. castellanii cysts.

\section{Discussion}

The treatment of Acanthamoeba keratitis is challenging and chances of recurrent infection are high [7]. Moreover, if it is not treated promptly and aggressively, it may lead to blindness. Contact lens wearers are at an increased risk because of ineffective lens hygiene, use of homemade contact lens solution, limescale, hard water, and use of expired contact lens solutions as potential risk factors [9,20-22]. The cascade of events triggering Acanthamoeba keratitis need to be understood to target treatment regimens at specific molecules or mechanisms, to explore diseasemodifying strategies.

Given the nature of the disease and its devastating consequences, it is important to increase public awareness and 
A)

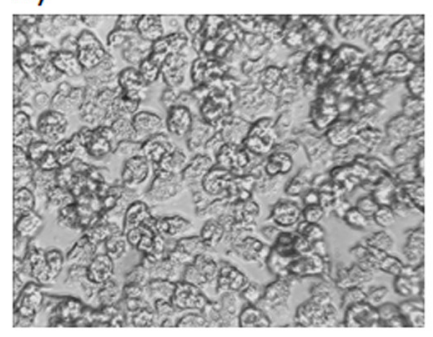

D)

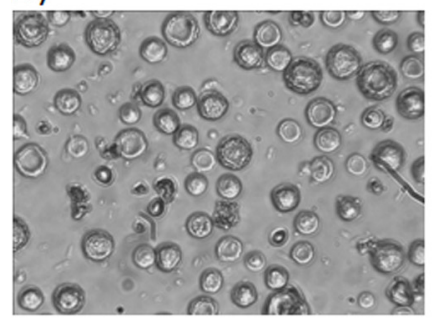

G)

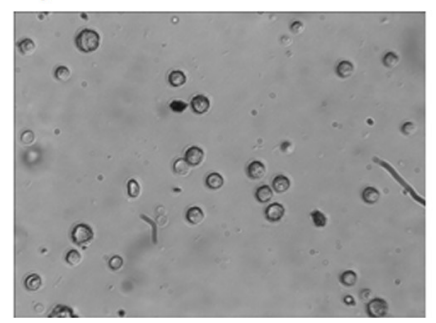

B)

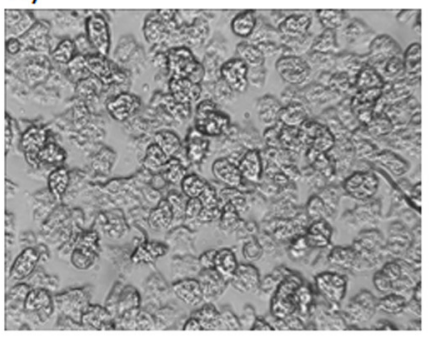

E)

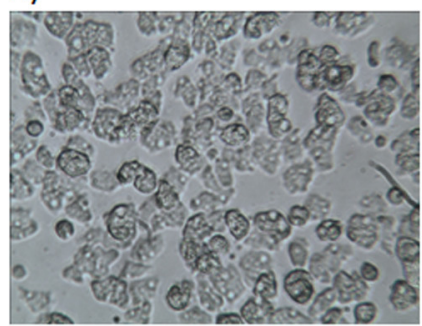

H)

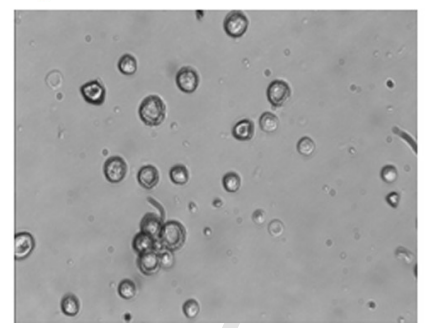

C)

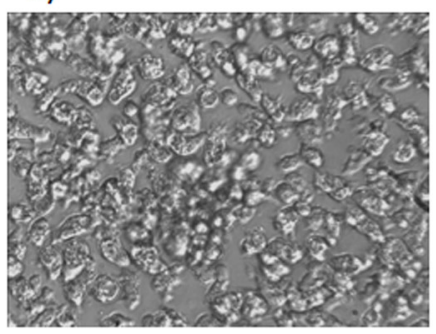

F)

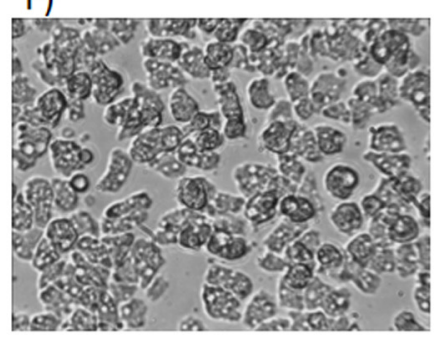

I)

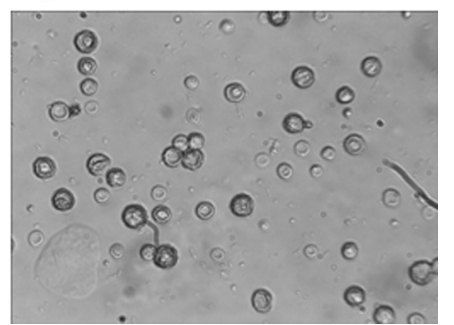

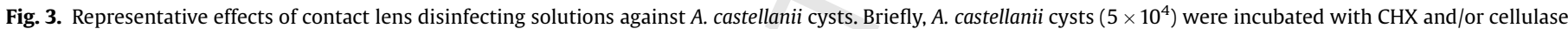

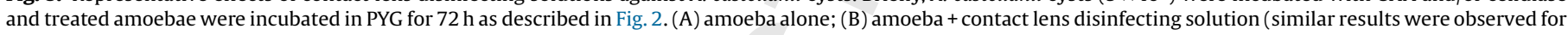

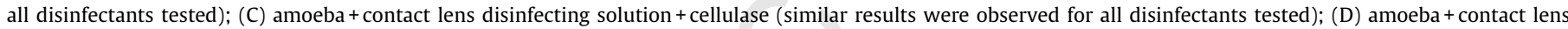

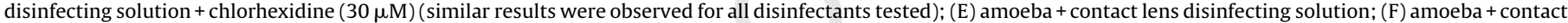

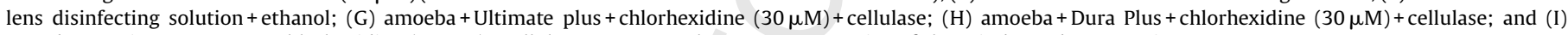
amoeba + Opti-Free Express + chlorhexidine $(30 \mu \mathrm{M})+$ cellulase. X250. Results are representative of three independent experiments.

improve preventative strategies, especially among contact lens users who are at increased risk. Of concern, recent studies demonstrated inefficacy of marketed contact lens disinfectants in destroying A. castellanii, in particular against the cyst stage [14]. Cysts are partially made of cellulose, hence we proposed that adding cellulase and chlorhexidine will be a promising strategy in targeting A. castellanii trophozoites and cysts.

Cellulase used in the present study was isolated from Trichoderma reesei, a non-pathogenic fungal strain that serves as a major producer of biomass degrading enzymes. Cellulases and most hemicellulases belong to a group of enzymes known as glycoside hydrolases. In most cases, cellulases have a small independently folded carbohydrate-binding module which is connected to the catalytic domain by a flexible linker. The carbohydrate binding module increases the enzyme activity by binding to the crystalline cellulose. Cellulases follow two different catalytic mechanisms; the retaining and the inverting mechanisms. In both mechanisms, two catalytic carboxylate residues are involved and catalyze the reaction by acid-base catalysis [23]. Chlorhexidine is a commonly used disinfectant. It is a positively charged molecule that interacts effectively with the negatively charged membranes of different species of Acanthamoeba disrupting the cell membranes and interfering with osmosis, resulting in leakage of cytoplasmic contents and cell death [24,25]. It is on the list of the most important medication needed in a basic health system determined by World Health Organization [26] that is widely used as an antiseptic.
When tested alone, none of the contact lens disinfecting solutions completely destroyed $A$. castellanii trophozoites and cysts. The addition to chlorhexidine destroyed trophozoites but did not completely destroyed cysts, as viable trophozoites emerged when treated cysts were inoculated in fresh growth medium, PYG. In contrast, chlorhexidine plus cellulase-treated cysts were abolished and they were unable to revive in the growth medium, PYG. A likely explanation for these findings is that cellulase destroyed cyst walls, allowing chlorhexidine to target cell membranes of resident trophozoite resulting its destruction. Overall, Acanthamoeba trophozoites are highly sensitive to chlorhexidine and a combination of cellulase plus chlorhexidine proved lethal against both the cyst form and the trophozoite form and exhibited $100 \%$ kill rate. Thus the absence of cyst walls degrading enzymes in contact lens disinfecting solutions render them ineffective against Acanthamoeba cysts. Although toxic effects of new formulations on host cells needs to be determined, but these findings suggest that the addition of cyst walls degrading molecules in contact lens disinfecting solutions will enhance their efficacy in eradicating Acanthamoeba. Additionally, the addition of cyst walls degrading molecules in drug formulation in the treatment of Acanthamoeba keratitis. Future studies will unravel the precise biochemistry of cyst walls of Acanthamoeba to identify additional targets for the development of effective contact lens disinfecting solutions as well as chemotherapeutic approaches. 


\section{Authors' contribution}

RS and FA conceived the study. NAK and RS designed the experiments. All experiments were performed by FA under the supervision of FAY, NAK and RS. FAY and FA performed analyses and interpretations. FA wrote the first draft of the manuscript. FAY, NAK, and RS corrected the manuscript. All authors approved the manuscript.

\section{Acknowledgments}

This work was funded by Aga Khan University, Pakistan and Sunway University, Malaysia.

\section{References}

[1] F. Marciano-Cabral, G. Cabral, Acanthamoeba spp. as agents of disease in humans, Clin. Microbiol. Rev. 16 (2003) 273-307.

[2] N.A. Khan, Acanthamoeba: biology and increasing importance in human health, FEMS Microbiol. Rev. 30 (2006) 564-595.

[3] G.S. Visvesvara, H. Moura, F.L. Schuster, Pathogenic and opportunistic freeliving amoebae: Acanthamoeba spp., Balamuthia mandrillaris, Naegleria fowleri, and Sappinia diploidea, FEMS Immunol. Med. Microbiol. 50 (2007) 1-26.

[4] D.B. Jones, G.S. Visvesvara, N.M. Robinson, Acanthamoeba polyphaga keratitis and Acanthamoeba uveitis associated with fatal meningoencephalitis, Trans. Ophthalmol. Soc. U. K. 95 (1975) 221-232.

[5] A. Chawla, M. Armstrong, F. Carley, Acanthamoeba keratitis-an increasing incidence, Cont. Lens Anterior Eye 37 (2014) 120.

[6] C. Jiang, X. Sun, Z. Wang, Y. Zhang, Acanthamoeba keratitis: clinical characteristics and management, Ocul. Surf. 13 (2015) 164-168.

[7] J.J. Perez-Santonja, S. Kilvington, R. Hughes, A. Tufail, M. Metheson, J.K.G. Dart, Persistently culture positive Acanthamoeba keratitis; in vivo resistance and in vitro sensitivity, Ophthalmology 110 (2003) 1593-1600.

[8] M. Derda, P. Solarczyk, M. Cholewiński, E. Hadaś, Genotypic characterization of amoeba isolated from Acanthamoeba keratitis in Poland, Parasitol. Res. 114 (2015) 1233-1237.

[9] J. Lorenzo-Morales, C.M. Martín-Navarro, A. López-Arencibia, F. ArnalichMontiel, J.E. Piñero, B. Valladares, Acanthamoeba keratitis: an emerging disease gathering importance worldwide, Trends Parasitol. 29 (2013) 181-187.

[10] K. Bryant, J. Bugante, T. Chang, S. Chen, J. Rosenberg, R. Hammond, K. McConnell, R. Sanderson, J. Elm, M. Nakata, C. Wakida, C. Austin, J. Bestudik, M. G. Bordson, C. Conover, L. Granzow, A. Pelletier, V. Rea, A. Chu, E. Luckman, K. Signs, J. Harper, T. Damrow, E. Mosher, K. Kruger, E. Saheli, M. Cassidy, J. Hatch, A. Weltman, E.J. Garcia Rivera, Y. Garcia, M.A. Kainer, J. Archer, C. Joslin, P. Cernoch, D. Jones, M. Hamill, A. Matoba, S. Pflugfelder, K. Wilhelmus, S. Beavers, T. Chen, K. Christian, M. Cooper, D. Dufficy, M. Gershman, M. Glenshaw, A. Hall, S. Holzbauer, A. Huang, A. Langer, Z. Moore, A.S. Patel, L.R.
Carpenter, J. Schaffzin, J. Su, I. Trevino, T. Weiser, P. Wiersma, S. Lorick, J.R. Verani, Acanthamoeba keratitis multiple states, 2005-2007, Morb. Mortal. Wkly. Rep. 56 (2007) 532-534.

[11] Health Canada, Recall of complete all- in-one Contact Lens Care Solution. http://news.gc.ca/web/article-en.do?crtr.sj1D=\&mthd=advSrch\&crtr. mnthndVl=\&nid=310159\&crtr.dpt1D=\&crtr.tp1D=\&crtr.lc1D=\&crtr. yrStrtVl=2008\&crtr.kw=\&crtr.dyStrtVl=26\&crtr.aud1D=\&crtr. mnthStrtVl=2\&crtr.yrndVl=\&crtr. dyndVl=\&_ga=1.225409370.1110815040.1441598834, (accessed 15.07.15).

[12] S. Hsieh, Suits over contact lens solution move forward, Wisconsin Law J. http://www.wislawjournal.com/article.cfm/2009/01/12/Suits-over-contactlens-solution-move-forward,2015 (accessed 16.07.15).

[13] K. Hiti, J. Walochnik, E.M. Haller-Schober, C. Faschinger, H. Aspöck, Viability of Acanthamoeba after exposure to a multipurpose disinfecting contact lens solution and two hydrogen peroxide systems, Br. J. Ophthalmol. 86 (2002) 144-146.

[14] S. Lakhundi, N.A. Khan, R. Siddiqui, Inefficacy of marketed contact lens disinfection solutions against keratitis-causing Acanthamoeba castellanii belonging to the T4 genotype, Exp. Parasitol. 141 (2014) 122-128.

[15] T.J. Byers, B.G. Kim, L.E. King, E.R. Hugo, Molecular aspects of the cell cycle and Q6 encystment of Acanthamoeba, Rev. Infect. Dis. (Suppl. 5) (1991) S373-S384.

[16] R.A. Weisman, Differentiation in Acanthamoeba castellanii, Annu. Rev. Microbiol. 30 (1976) 189-219.

[17] D. Lloyd, Encystment in Acanthamoeba castellanii: a review, Exp. Parasitol. 145 (2014) S20-7.

[18] R. Dudley, E.L. Jarroll, N.A. Khan, Carbohydrate analysis of Acanthamoeba castellanii, Exp. Parasitol. 122 (2009) 338-343.

[19] F.A. Yousuf, Z. Yousuf, J. Iqbal, R. Siddiqui, H. Khan, N.A. Khan, Interactions of neuropathogenic Escherichia coli K1 (RS 218) and its derivatives lacking genomic islands with phagocytic Acanthamoeba castellanii and nonphagocytic brain endothelial cells, Biomed Res. Int. (2014) (article ID: 265424).

[20] S. Kilvington, T. Gray, J. Dart, et al., Acanthamoeba keratitis: the role of domestic tap water contamination in the United Kingdom, Invest. Ophthalmol. Vis. Sci. 45 (2004) 165-169.

[21] C.F. Radford, D.C. Minassian, J.K.G. Dart, Acanthamoeba keratitis in England and Wales: incidence, outcome, and risk factors, Br. J. Ophthalmol. 86 (2002) 536-542.

[22] C.E. Joslin, E.Y. Tu, T.T. McMahon, et al., Epidemiological characteristics of a Chicago-area Acanthamoeba keratitis outbreak, Am. J. Ophthalmol. 142 (2006) 212-217.

[23] M. Dashtban, H. Schraft, W. Qin, Fungal bioconversion of lignocellulosic residues; opportunities \& perspectives, Int. J. Biol. Sci. 5 (2009) 578-595

[24] B. Athanassiadis, P.V. Abbott, L.J. Walsh, The use of calcium hydroxide, antibiotics and biocides as antimicrobial medicaments in endodontics, Aust. Dent. J. 52 (Suppl. 1) (2007) S64-S82.

[25] D.S. Bezdenezhnykh, E.V. Rusanova, A.A. Nikitin, N.V. Malychenko, In vitro comparison of antibacterial properties of antiseptics used in periodontology, Stomatologiia (Mosk) 91 (2012) 20-21.

[26] WHO, Model List of Essential Medicines, World Health Organization. http://apps.who.int/iris/bitstream/10665/93142/1/EML_18_eng.pdf?ua=1, 2013 (accessed 20.07.15). 